\title{
Multiplex PCR Using Conserved and Species-Specific 16S rRNA Gene Primers for Simultaneous Detection of Actinobacillus actinomycetemcomitans and Porphyromonas gingivalis
}

\author{
SIMON DANGTUAN TRAN AND JOEL D. RUDNEY* \\ Department of Oral Science, School of Dentistry, University of Minnesota, Minneapolis, Minnesota 55455
}

Received 15 April 1996/Returned for modification 31 July 1996/Accepted 12 August 1996

\begin{abstract}
Actinobacillus actinomycetemcomitans and Porphyromonas gingivalis are strongly associated with periodontitis. However, little is known about their distribution in periodontally healthy individuals, because culturing techniques are not sufficiently sensitive. A modified multiplex PCR was developed to address that question. Our method uses two species-specific forward primers in combination with a single reverse primer. These primers target variable and conserved regions of the $16 \mathrm{~S}$ rRNA gene. Sensitivity was determined by testing serial dilutions of $A$. actinomycetemcomitans and $P$. gingivalis cells. Primer specificity was tested against (i) six $A$. actinomycetemcomitans strains and four $P$. gingivalis strains, (ii) seven different species of oral bacteria, and (iii) supra- and subgingival plaque from 20 subjects. The multiplex PCR had a lower limit of detection of $2 A$. actinomycetemcomitans and $30 P$. gingivalis cells. Species-specific amplicons were obtained for all $A$. actinomycetemcomitans and $P$. gingivalis strains tested and did not occur with seven other bacterial species unless $A$. actinomycetemcomitans and $\boldsymbol{P}$. gingivalis were added. Neither target species was detected in supragingival plaque; $A$. actinomycetemcomitans was detected in one subgingival specimen, and $P$. gingivalis was detected in another. When plaque samples were spiked with $10 \mathrm{~A}$. actinomycetemcomitans cells and 100 P. gingivalis cells, species-specific amplicons were detected. These findings show our multiplex PCR to be highly sensitive and specific while allowing simultaneous detection of $A$. actinomycetemcomitans and $P$. gingivalis. This assay has potential applications in epidemiological studies, diagnosis, treatment planning, and monitoring of periodontal pathogens.
\end{abstract}

Periodontitis refers to a set of diseases that cause inflammation and loss of supporting structures of the teeth. The pattern of attack can be quite localized, so that patients' mouths will typically show both diseased and healthy sites (15). Persons who accumulate large quantities of dental plaque have been considered to be at risk for periodontitis. However, current thinking suggests that the development of disease requires both a susceptible host and a pathogenic flora (34). Host susceptibility may reflect genotypic predispositions that can be exacerbated by high-risk behaviors such as smoking and poor oral hygiene (35). Pathogenic floras consist predominantly of gram-negative anaerobes, but certain species are strongly associated with teeth that show clinical evidence of disease (15).

A number of putative periodontal pathogens have been identified. The most convincing evidence of periodontal pathogenicity exists for Actinobacillus actinomycetemcomitans and Porphyromonas gingivalis. A actinomycetemcomitans and/or $P$. gingivalis frequently can be cultured from plaque samples removed from subgingival pockets around teeth affected by periodontal disease. They are much less likely to be recovered by culture from healthy teeth in diseased individuals. Each species also displays potential virulence factors (e.g., leukotoxins, high levels of protease activity, tissue invasion) which could contrib-

\footnotetext{
* Corresponding author. Mailing address: Department of Oral Science, University of Minnesota, School of Dentistry, 515 Delaware St. S.E., 17-252 Moos Tower, Minneapolis, MN 55455. Phone: (612) 6247199. Fax: (612) 626-2651. Electronic mail address: jrudney@maroon .tc.umn.edu.
}

ute to the loss of gingival attachment that occurs as periodontitis progresses (15).

Teeth positive for $A$. actinomycetemcomitans and/or $P$. gingivalis may be at higher risk for periodontal disease (15), but the presence or absence of these organisms is not sufficient to establish a diagnosis. That must be done through clinical examination. It is not yet clear whether these bacteria are exogenous pathogens or are endogenous members of the oral flora that may become pathogenic in the presence of other risk factors (22). To address this question, it is important to know whether small numbers of $A$. actinomycetemcomitans and/or $P$. gingivalis cells are typically found in healthy periodontal sites.

Researchers have tried to develop techniques to detect and to quantitate these putative pathogens (36). Culture has been used in most epidemiological and clinical studies (31), although techniques such as immunoassays, enzyme assays, and nucleic acid probe assays indicate that $A$. actinomycetemcomitans and $P$. gingivalis are present in the oral cavity more frequently than anaerobic culturing can detect $(20,31)$. However, the techniques mentioned above still require approximately $10^{3}$ to $10^{5}$ targets per sample specimen.

The PCR can lower the limit of bacterial detection. In recent years, there has been great interest in PCR-based tests which use the bacterial small subunit $16 \mathrm{~S}$ rRNA gene (16S rDNA) to detect bacterial pathogens. Nucleotide sequences of some portions of the $16 \mathrm{~S}$ rDNA have been highly conserved. However, other regions of this gene are hypervariable. Conserved $16 \mathrm{~S}$ rDNA sequences provide PCR primers which facilitate the collection of large amounts of DNA for sequence analysis of species-specific variable regions. Those regions in turn provide DNA probes and PCR primers for unique identification of 
16S rRNA gene

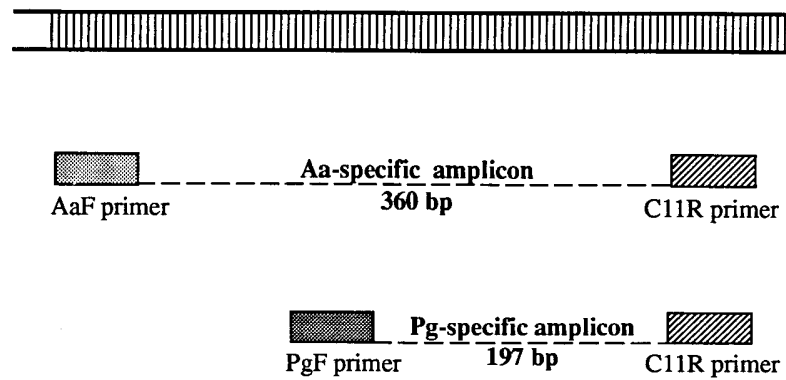

FIG. 1. Multiplex PCR using conserved and species-specific 16S rDNA primers for simultaneous detection of $A$. actinomycetemcomitans (Aa) and $P$. gingivalis $(\mathrm{Pg})$. Shown is a schematic drawing of the location where the primers anneal to the bacterial $16 \mathrm{~S}$ rDNA. The approximate sizes of the species-specific amplicons generated are also depicted.

bacterial species. Most tests have emphasized the detection of only a single species. However, sets of $16 \mathrm{~S}$ rDNA-based primers can be combined to detect more than one species in a single patient sample. The general approach of combining multiple primers in a single reaction is called multiplex PCR (5).

The objective of this study is to develop, optimize, and evaluate a multiplex PCR technique which uses conserved and species-specific $16 \mathrm{~S}$ rDNA primers to simultaneously detect $A$. actinomycetemcomitans and $P$. gingivalis. The rationale in developing this bacterial detection technique is that both species are strongly associated with periodontitis. However, little is known about the distribution of these putative pathogens around periodontally healthy teeth, because microbiological culturing techniques are not sufficiently sensitive. Because of its ability to detect low numbers of bacteria and its rapidity of plaque sample analysis, a PCR-based technique may be the method of choice to investigate the natural distribution of $A$. actinomycetemcomitans and $P$. gingivalis and to localize their reservoirs.

\section{MATERIALS AND METHODS}

Primer design and selection. A literature search found a total of four published $A$. actinomycetemcomitans $16 \mathrm{~S}$ rRNA oligonucleotide probes and eight $P$. gingivalis probes $(1,6,7,9,10,19,29)$. These probes were selected as possible species-specific forward primers. For the selection of the reverse primer, a total of seven prospective conserved (universal) 16S rDNA primers were identified (27). These reverse primers can hybridize to any bacterial $16 \mathrm{~S}$ rDNA and can be combined with each species-specific forward primer to produce amplicons of different sizes that can be subsequently resolved on an agarose gel.

Suitable primers and PCR products were defined by using the program PRIME (Genetics Computer Group, Madison, Wis.). All 16S rDNA sequences of $A$. actinomycetemcomitans and $P$. gingivalis strains stored in the GenBankEMBL database were used as DNA templates in PRIME. The strains and GenBank accession numbers were A. actinomycetemcomitans ATCC 29522 (M75036), ATCC 29523 (M75038), ATCC 29524 (M75037), ATCC 33384 (M75039), and FDC Y4 (M75035) and $P$. gingivalis ATCC 33277 (L16492; $\mathrm{X} 73964)$. The specificities of the prospective primers were tested by the program FastA (Genetics Computer Group) against all existing DNA sequence information stored in GenBank-EMBL, and by program CHECK-PROBE from the Ribosomal Database Project (17). No sequences completely homologous to prospective $A$. actinomycetemcomitans and $P$. gingivalis forward primers were found in $16 \mathrm{~S}$ rDNAs for 95 other oral bacterial species in these databases.

We identified a set of primers with minimal differences in annealing temperature; the calculated optimal annealing temperatures were 58.4 and $60.7^{\circ} \mathrm{C}$ for the $A$. actinomycetemcomitans and $P$. gingivalis primers, respectively. The expected product lengths were $360 \mathrm{bp}$ for $A$. actinomycetemcomitans and $197 \mathrm{bp}$ for $P$. gingivalis (Fig. 1). The nucleotide sequences of the three selected and modified $16 \mathrm{~S}$ rDNA primers were as follows: $A$. actinomycetemcomitans forward primer (AaF), 5'-ATT GGG GTT TAG CCC TGG TG-3' (Escherichia coli positions 870 to 896$) ; P$. gingivalis forward primer $(\mathrm{PgF}), 5^{\prime}$-TGT AGA TGA CTG ATG GTG AAA ACC-3' (E. coli positions 1039 to 1063); and conserved reverse primer (C11R), 5'-ACG TCA TCC CCA CCT TCC TC-3' (E. coli positions, 1227 to 1246). The nucleotide positions given were obtained by aligning the sequences of $A$. actinomycetemcomitans ATCC 29522 (M75036) and $P$. gingivalis ATCC 33277 (L16492) with that of E. coli (J01695) by using the subalign command from the Ribosomal Database Project (17). The selected oligonucleotide primers were synthesized by a commercial vendor (Life Technologies, Grand Island, N.Y.).

Bacteria and growth conditions. ATCC reference strains and stored isolates obtained from the University of Minnesota Department of Oral Science culture collections were grown anaerobically in Todd-Hewitt broth (Difco Laboratories, Detroit, Mich.) supplemented with hemin $(5 \mu \mathrm{g} / \mathrm{ml})$ and menadione $(0.5 \mu \mathrm{g} / \mathrm{ml})$. In order to minimize contamination by exogenous bacterial DNA, disposable sterile labware was used for bacterial growth, washing, and storage procedures. When glass tubes were utilized, they were soaked in a 1:10 dilution of a $5 \%$ solution of sodium hypochlorite before being washed and autoclaved (26). Bacteria were harvested by centrifugation, washed twice, and stored in TE buffer (10 $\mathrm{mM}$ Tris-HCl [pH 7.5], $1 \mathrm{mM}$ EDTA [pH 8.0]) or 0.01 M phosphate-buffered saline (PBS) $(\mathrm{pH} \mathrm{7.4,0.9 \%} \mathrm{NaCl})$ at $4^{\circ} \mathrm{C}$. Each bacterial sample was dispersed, by repeated cycles of sonication for $5 \mathrm{~s}$ at low intensity (Sonic Dismembrator 50 ; Fisher Scientific, Pittsburgh, Pa.) and vortexing, until a homogeneous mixture could be observed.

Preparation of bacterial DNA templates for multiplex PCR. Bacterial DNA was extracted with a commercial DNA-releasing reagent (Genereleaser; Bioventures, Murfreesboro, Tenn.). A $6-\mu l$ aliquot of a bacterial broth culture diluted in PBS or $6 \mu \mathrm{l}$ of a plaque sample placed directly in $250 \mu \mathrm{l}$ of PBS was mixed with $10 \mu \mathrm{l}$ of Genereleaser in a $0.5-\mathrm{ml}$ thin-walled PCR tube (Perkin-Elmer, Foster City, Calif.). A 50- $\mu$ l mineral oil overlay was added, and the mixture was microwaved for $6 \mathrm{~min}(4,500 \mathrm{~W}$-min).

Multiplex PCR with conserved and species-specific primers. The approach previously described by Chamberlain and Chamberlain (4) was used to optimize our modified multiplex PCR for the detection of $A$. actinomycetemcomitans and $P$. gingivalis. Optimization of the primer concentration was performed by mixing primers $\mathrm{AaF}, \mathrm{PgF}$, and $\mathrm{C} 11 \mathrm{R}$ together at several concentrations between 0.25 and $1.0 \mu \mathrm{M}$ and adding $10^{6} \mathrm{~A}$. actinomycetemcomitans cells and $10^{6} \mathrm{P}$. gingivalis cells. We started with equal concentrations of $\mathrm{AaF}, \mathrm{PgF}$, and $\mathrm{C} 11 \mathrm{R}$. However, the $A$. actinomycetemcomitans amplicon was produced at a higher efficiency than was the $P$. gingivalis amplicon, even though the estimated number of cells for each species was equal. The ratio of primer concentrations was adjusted so that both amplicons were produced with high efficiency. The AmpliTaq (PerkinElmer) DNA polymerase concentration was optimized by testing concentrations between 2.5 and 4.5 U. Amplification bands other than the 197- and 360-bp products expected did not occur with pure cultures. Therefore, we decided to use the calculated optimal annealing temperature of $60.7^{\circ} \mathrm{C}$. The protocol described below was then used for all further experiments.

The volume used for each multiplex PCR was $50 \mu \mathrm{l}$ (34 $\mu \mathrm{l}$ for the master mix and $16 \mu \mathrm{l}$ of extracted DNA and DNA-releasing reagent). A "hot-start" step was included in our protocol and consisted of (i) holding the template at $80.0^{\circ} \mathrm{C}$ for at least $5 \mathrm{~min}$, (ii) adding $26 \mu \mathrm{l}$ of master mix but excluding the deoxynucleoside triphosphates (dNTPs), (iii) raising the temperature to $90.0^{\circ} \mathrm{C}$, and (iv) adding 8 $\mu l$ of dNTPs. The amplification reaction mixture (master mix) contained $10 \mathrm{mM}$ Tris-HCl, $50 \mathrm{mM} \mathrm{KCl} \mathrm{(10 \times} \mathrm{PCR} \mathrm{Buffer} \mathrm{II;} \mathrm{Perkin-Elmer),} 2.5 \mathrm{mM} \mathrm{MgCl}, 0.25$ $\mu \mathrm{M}$ primer $\mathrm{AaF}, 0.80 \mu \mathrm{M}$ primer $\mathrm{PgF}, 0.50 \mu \mathrm{M}$ primer $\mathrm{C} 11 \mathrm{R}$, and $3.5 \mathrm{U}$ of AmpliTaq. The dNTPs included $200 \mu \mathrm{M}$ (each) dATP, dCTP, and dGTP (Promega, Madison, Wis.) and $600 \mu \mathrm{M}$ dUTP (Boehringer Mannheim, Indianapolis, Ind.). The cycling parameters consisted of 35 cycles run at the fastest ramp time available: $95.0^{\circ} \mathrm{C}$ for $1 \mathrm{~min}$ (except $5 \mathrm{~min}$ for the first cycle), $60.7^{\circ} \mathrm{C}$ for $1 \mathrm{~min}$, and $72.0^{\circ} \mathrm{C}$ for $2 \mathrm{~min}$ (except $10 \mathrm{~min}$ for the last cycle). The samples were held at $4^{\circ} \mathrm{C}$ until analysis by agarose gel electrophoresis.

Standard quality control steps were included in each PCR experiment to avoid and to detect any possible exogenous bacterial DNA contamination or any amplicon carryover contamination, as described by Kwok and Higuchi (16) and Prince and Andrus (26). Additional preventive measures to avoid false positives with PCR included preparation of PCR reagents (master mix) inside a portable chamber equipped with an air filter and a UV light (Cleansphere CA100; Safetech Ltd.), replacement of dTTP by dUTP to allow the use of uracil-DNA glycosylase (Boehringer Mannheim) if needed to eliminate amplicon contamination (21), and the use of a negative control without template DNA. Each experiment also included a positive control containing $10 \mathrm{~A}$. actinomycetemcomitans cells and $100 P$. gingivalis cells from pure cultures. An additional positive control was added for experiments with plaque samples (see below).

Post-multiplex PCR gel electrophoresis. A 20- $\mu$ l aliquot of amplified sample from each PCR tube was electrophoresed through a $2 \%$ agarose gel (Fisher Scientific, Fair Lawn, N.J.) in $0.5 \times$ Tris-borate-EDTA (TBE) buffer $(0.045 \mathrm{M}$ Tris-borate, $0.001 \mathrm{M}$ EDTA) for $2 \mathrm{~h}$ at $80 \mathrm{~V}$. Amplification products were visualized and photographed under a UV light transilluminator (Fotodyne, Hartlands, Wis.) after $30 \mathrm{~min}$ of ethidium bromide $(1 \mu \mathrm{g} / \mathrm{ml})$ staining. The molecular weights of the amplicons were determined by comparison to commercial DNA molecular weight markers (number VIII; Boehringer Mannheim). Two independent examiners scored photographs for the presence or absence of A. actinomycetemcomitans and $P$. gingivalis amplicons.

Determination of the limit of detection. The lower limit of detection was defined as the smallest number of bacteria in a sample that could be detected by our modified multiplex PCR. This was determined by serial dilution of a mixture of pure cultures of $A$. actinomycetemcomitans (ATCC 29522) and P. gingivalis 
(ATCC 33277) cells. Dilutions were performed on the basis of triplicate viable and microscopic counts. They ranged from $1.75 \times 10^{6}$ to 0 cells for each species (by 10-fold dilutions). In addition to the studies on the pure cultures, studies were done on one supra- and one subgingival plaque sample that were spiked with serial dilutions of $A$. actinomycetemcomitans and $P$. gingivalis cells.

Validation of primer specificity. Primer specificity was defined as the ability of a primer to anneal specifically to only $A$. actinomycetemcomitans and $P$. gingivalis $16 \mathrm{~S}$ rDNAs. The specificities of the primers were tested against the following organisms: (i) six A. actinomycetemcomitans strains (ATCC strains 29522, 29524, 33384, 43717, 43718, and 43719) and four $P$. gingivalis strains (ATCC 33277 and clinical isolates W-50, 381, and 17-5), and (ii) seven different species of oral bacteria (Actinomyces naeslundii ATCC 12104, Bacteroides forsythus ATCC 43037, Campylobacter rectus ATCC 33238, Eikenella corrodens ATCC 43278, Fusobacterium nucleatum ATCC 10953, Prevotella intermedia ATCC 25611, and Streptococcus sanguis ATCC 10556) mixed together in suspensions containing greater than $10^{7}$ cells for each species.

Plaque samples. Supra- and subgingival plaque samples were collected from 18 dentists and 2 dental assistants following procedures approved by the University of Minnesota Institutional Review Board. Each subject had one supraand one subgingival plaque sample collected from sites of two anterior teeth meeting all of the following criteria for good periodontal health: gingival index, 0 or 1 ; probing depth, $\leq 3 \mathrm{~mm}$; and attachment level, $\leq 1 \mathrm{~mm}$. Plaque samples were taken with sterile curettes, placed in $250 \mu \mathrm{l}$ of PBS, and dispersed by sonication and vortexing. DNA was then extracted directly from $6 \mu \mathrm{l}$ of each plaque suspension, as described above.

Each plaque sample was run in three different ways: (i) alone, (ii) spiked with $10 \mathrm{~A}$. actinomycetemcomitans cells and $100 \mathrm{P}$. gingivalis cells, and (iii) in a nonmultiplex PCR with a pair of primers targeting the Actinomyces naeslundii type I and type II fimbrial genes (S1 primer, 5'-GTC CAC GTC TAC CCC AAG AAC-3'; AS1 primer, 5'-CAG GAA GAT GAC GCC GTT GGC A-3'; expected product lengths, approximately 993 bp) (8). Because we assumed Actinomyces naeslundii to be highly prevalent in supra- and subgingival plaque (24), its detection in a plaque sample would rule out the possibility that a sample was negative for $A$. actinomycetemcomitans and $P$. gingivalis because no bacteria were present.

\section{RESULTS}

Limit of detection. In pure cultures, the multiplex PCR simultaneously detected as few as $2 \mathrm{~A}$. actinomycetemcomitans and $30 P$. gingivalis cells (data not shown). The limit of detection was slightly higher in the spiked supra- and subgingival plaque samples, in which the multiplex PCR detected as few as 5 A. actinomycetemcomitans cells and $33 P$. gingivalis cells (Fig. 2).

Specificities of primers. Species-specific amplicons were observed for all $A$. actinomycetemcomitans and $P$. gingivalis strains tested. No $A$. actinomycetemcomitans- and $P$. gingivalis-specific amplicons were seen when our primers were used with seven other strains of oral species. Furthermore, when $10 \mathrm{~A}$. actinomycetemcomitans cells and $100 P$. gingivalis cells were added to mixtures of these seven oral species, A. actinomycetemcomitans- and $P$. gingivalis-specific amplicons were detected (data not shown).

Plaque samples. $A$. actinomycetemcomitans and $P$. gingivalis were not detected in 18 of 20 supragingival plaque samples from periodontally healthy sites. Two supragingival and are subgingival specimens did not demonstrate any amplicons for Actinomyces naeslundii fimbrial genes (see lane 14-B-V of Fig. 3 for an example). Of 20 subgingival plaque samples from periodontally healthy sites, $A$. actinomycetemcomitans was detected in one specimen (Fig. 3, lane 15-B-P) and $P$. gingivalis was found in another (Fig. 2, lane 7). The A. actinomycetemcomitans amplicon was very faint, suggesting the presence of relatively few cells in that plaque sample. The $P$. gingivalispositive subgingival plaque sample appeared to contain a relatively large number of cells, since the band density was greater than that seen when $3.3 \times 10^{6} \mathrm{P}$. gingivalis cells were added to supragingival plaque from the same person (Fig. 2). Further increases in the density of the $P$. gingivalis amplicon were not discernible when that subgingival sample was spiked with different dilutions of cells (Fig. 2).

To confirm primer specificity, all plaque samples were

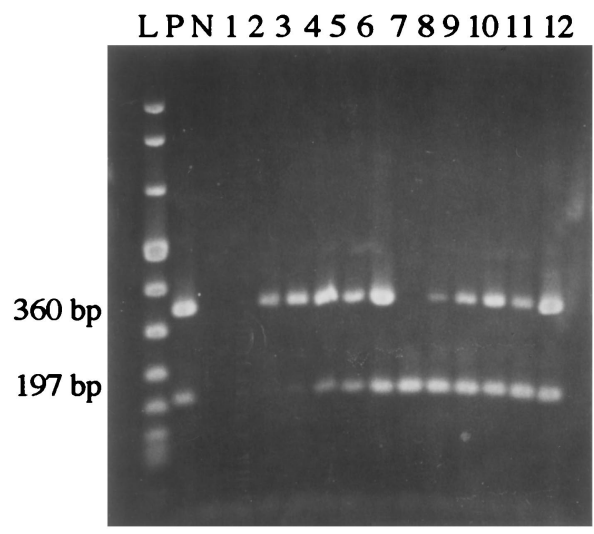

FIG. 2. The limit of detection of multiplex PCR in artificially infected plaque. Lane 1, supragingival plaque sample from a periodontally healthy dentist; no amplicons were seen in this multiplex PCR. Lanes 2 to 6 , the same supragingival plaque sample spiked with different numbers of cells; $A$. actinomycetemcomitans is represented by a 360-bp amplicon, and $P$. gingivalis is represented by a 197-bp amplicon. Lane 2, 5 A actinomycetemcomitans cells and $3 P$. gingivalis cells; lane 3, $55 \mathrm{~A}$. actinomycetemcomitans cells and $33 \mathrm{P}$. gingivalis cells; lane $4,550 \mathrm{~A}$ actinomycetemcomitans cells and $330 P$. gingivalis cells; lane $5,5,500 \mathrm{~A}$. actinomycetemcomitans cells and 3,300 P. gingivalis cells; lane $6,5 \times 10^{6} \mathrm{~A}$. actinomycetemcomitans cells and $3.3 \times 10^{6} P$. gingivalis cells. Lane 7 , subgingival plaque sample from the same dentist; endogenous $P$. gingivalis is represented by a 197-bp amplicon, but no A. actinomycetemcomitans amplicon was seen in this multiplex PCR. Lanes 8 to 12 , the same subgingival plaque sample as in lane 7 but spiked with $A$. actinomycetemcomitans and $P$. gingivalis cells as in lanes 2 to 6 above. Lane L, (ladder) DNA molecular weight marker with fragments ranging in size from 19 to $1,114 \mathrm{bp}$; the fragments observed on this $2 \%$ agarose gel correspond to $1,114,900,692,501$ to $489,404,320,242,190$, and $147 \mathrm{bp}$. Lane $\mathrm{P}$, positive control with $10 \mathrm{~A}$. actinomycetemcomitans cells and $100 \mathrm{P}$. gingivalis cells in PBS. Lane N, negative control with multiplex PCR primers in PBS

spiked with $10 \mathrm{~A}$. actinomycetemcomitans cells and $100 \mathrm{P}$. gingivalis cells. Specific amplicons for A. actinomycetemcomitans and $P$. gingivalis were detected in all of these artificially infected supra- and subgingival plaque samples (Fig. 3, all lanes ending in S).

\section{DISCUSSION}

In recent years, several researchers in the field of periodontology have successfully developed PCR-based techniques for detection of $A$. actinomycetemcomitans or $P$. gingivalis $(1,3,11$, $12,14,30,33)$. The reported lower limits of detection for either species ranged from 100 to 1,000 cells in plaque samples. Those PCR-based assays targeted either the fimbrial gene, the collagenase gene, or the superoxide dismutase gene of $P$. gingivalis or the leukotoxin A gene of $A$. actinomycetemcomitans. Albandar and Lyngstadaas (1) were able to detect $A$. actinomycetemcomitans by targeting specific regions of the $16 \mathrm{~S}$ rDNA. However, only one DNA sequence (or gene) can be amplified by conventional PCR; therefore, a separate reaction tube is needed for the detection of each bacterial species of interest.

Time, effort, and cost can be saved by amplifying multiple sequences in a single reaction tube. Recently, a multiplex PCR for simultaneous detection of 5 to $50 \mathrm{~A}$. actinomycetemcomitans and $P$. gingivalis cells per sample has been reported (32). That approach required two separate sets of $16 \mathrm{~S}$ rDNA-based species-specific primers (i.e., a total of four primers) to detect $A$. actinomycetemcomitans and $P$. gingivalis. Our technique modifies that approach by using one specific forward primer per species in combination with a single conserved reverse primer (i.e., a total of three primers) (Fig. 1). Our modified multiplex PCR assay could detect as few as $2 \mathrm{~A}$. actinomyce- 

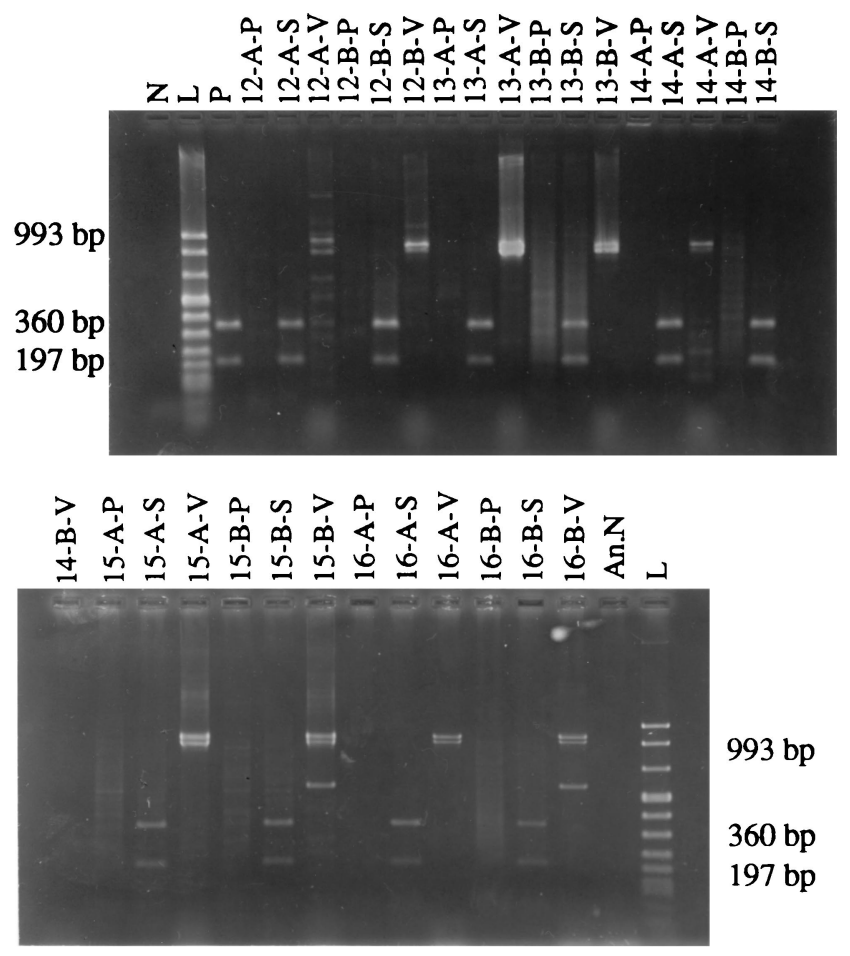

FIG. 3. Multiplex PCR of supra- and subgingival plaque samples from periodontally healthy dentists. All samples shown were run on the same gel by placing two combs in different locations. The top and bottom portions of the gel are presented as two separate panels. Lane N, negative control employing multiplex PCR primers in PBS; lane L, ladder ranging from 19 to 1,114 bp (same as that described in the legend to Fig. 2); lane $\mathrm{P}$, positive control with $10 \mathrm{~A}$. actinomycetemcomitans cells and 100 P. gingivalis cells in PBS; lane An.N, negative control employing Actinomyces naeslundii fimbrial primers in PBS. The coding system for plaque samples is as follows. The first part of the code (numbers 1 to 20 ) is the dentist identification number. The middle part of the code specifies whether the sample is supragingival (A) or subgingival (B). The last part of the code specifies whether the sample consists of plaque alone $(\mathrm{P})$, plaque spiked with $10 \mathrm{~A}$. actinomycetemcomitans cells and $100 \mathrm{P}$. gingivalis cells (S), or plaque with Actinomyces naeslundii fimbrial primers (V). In plaque alone, no species-specific amplicons for $A$. actinomycetemcomitans or $P$. gingivalis occur except in lane 15-B-P, where a faint amplicon corresponding to that expected for A. actinomycetemcomitans can be seen at $360 \mathrm{bp}$, and faint nonspecific bands are also visible. In spiked samples, specific amplicons for each species are clearly visible. With fimbrial primers, amplicons representing genes for type I and type II fimbriae can be seen at 993 bp (an additional unidentified amplicon is visible with these primers in subgingival plaque from dentists 15 and 16). Fimbrial amplicons are not seen in lane $14-\mathrm{B}-\mathrm{V}$.

temcomitans cells and $30 P$. gingivalis cells in pure cultures and as few as 5 A. actinomycetemcomitans cells and $33 P$. gingivalis cells in spiked plaque samples. Our approach is simpler and less expensive, with a comparable limit of detection.

Our approach also displays comparable primer specificity. Amplicons of the predicted sizes were obtained for all strains of $A$. actinomycetemcomitans and $P$. gingivalis tested, and those amplicons were not seen for seven other species tested in pure cultures. Neither of our species-specific forward primers showed complete homology to 16S rDNAs of any other oral species in current sequence databases. This suggests that similar results would have been obtained if pure cultures of additional species had been evaluated. In plaque samples, the specificities of our primers were tested against a multitude of other oral bacterial species (over 300 species are associated with supra- and subgingival plaque, and as many as 30 to 100 species may be recovered from a single periodontal pocket) (15). Occasionally, nonspecific bands were observed. However, their molecular weights were different from those of the $A$. actinomycetemcomitans and $P$. gingivalis amplicons, and they thus did not interfere with the interpretation of results (Fig. 3, lane 15-B-P).

As a control to verify the presence of bacteria in each plaque sample, we first used a pair of $16 \mathrm{~S}$ rDNA conserved primers. However, others have found that commercial preparations of Taq polymerase contain low levels of $16 \mathrm{~S}$ rDNA from bacteria used to synthesize that enzyme $(13,23)$. In our hands, such contamination appears to have resulted in the detection of a 16S rDNA amplicon even in sterile PBS (i.e., false-positive results) (data not shown). This conclusion was made after extensive testing to rule out other possible sources of exogenous bacterial DNA. These methods included filter sterilizing all solutions before autoclaving them, changing commercial suppliers of PCR reagents and equipments, performing the same multiplex PCR protocol in three different laboratories, aerobic and anaerobic culturing of our water supplies, and treating PCR reagents with DNase.

As an alternative control, a pair of primers targeting the fimbrial genes of Actinomyces naeslundii was run in a separate PCR tube (8). We sometimes observed nonspecific amplicons with the Actinomyces naeslundii fimbrial primers (e.g., Fig. 3, lane 15-B-V). That may have occurred because an annealing temperature of $60.7^{\circ} \mathrm{C}$ was not optimal for those primers. Such bands did not interfere with our use of the fimbrial primers to confirm the presence of oral bacteria. Two supragingival and one subgingival samples failed to show amplicons with those primers. Plaque was not visible on the surfaces from which those samples were taken, and it is likely that the total number of bacteria present was below the limit of detection for PCR.

Certain investigators believe that anaerobic cultural procedures may be inadequate as a primary reference standard ("gold standard") for the presence of periodontal pathogens $(20,25)$. Therefore, we decided not to culture the plaque specimens obtained. However, the specificity of a diagnostic test using our multiplex PCR to detect the presence of $A$. actinomycetemcomitans or $P$. gingivalis is likely to be high. No species-specific amplicons were detected in 20 supragingival plaque samples, and only 2 of 20 healthy subgingival sites were positive for target species in this periodontally healthy population. Diagnostic sensitivity also is likely to be high, since all 40 plaque samples became positive when artificially infected with $A$. actinomycetemcomitans and $P$. gingivalis cells in numbers well below the estimated 1,000-cell threshold for detection by culture (28). Crude estimates of cell numbers in plaque samples can be made by comparing the band intensities to those observed for a cell dilution series (Fig. 2). Precise measurements are more difficult to obtain, since PCR efficiency may vary among runs. A truly quantitative multiplex PCR would require internal standards designed to be added to every sample (18).

Periodontally healthy subjects were selected for evaluation of this multiplex PCR because we plan to use it to determine whether $A$. actinomycetemcomitans and/or $P$. gingivalis typically is found at low levels in sites without clinical evidence of disease. Findings from this limited pilot sample might support the view that these bacteria act as exogenous transmissible pathogens, since only 1 of 20 subjects was positive for each species. However, results may be biased because pilot subjects were dental practitioners who might be expected to make a strong effort to prevent periodontal disease in their own mouths. We are beginning multiplex PCR studies of $A$. actinomycetemcomitans and $P$. gingivalis prevalence in two very large series of stored plaque samples encompassing a full range of periodontal pathology, from complete health to severe disease 
$(2,34)$. Those studies should provide a more definite answer to the question of whether $A$. actinomycetemcomitans and $P$. gingivalis are exogenous pathogens or endogenous opportunists.

Potential clinical uses for our modified multiplex PCR include patient education to reinforce the importance of following preventive treatment regimens, identification of subjects (or teeth) at risk for onset or progression of periodontitis, and evaluation of the success of periodontal therapy. Also, it may be possible to detect other putative periodontal pathogens (e.g., B. forsythus, Peptostreptococcus micros, Prevotella intermedia, and spirochetes) by adding more species-specific forward primers to this multiplex PCR. Microbiological testing for periodontal pathogens has not been widespread in dentistry. However, clinical laboratories which test samples by mail have recently been established, and tests which can be performed in dentists' offices have also been introduced. Microbiological tests are most likely to be done to help the periodontist determine if antibiotics will be given to patients with severe disease. If testing also can identify sites at risk before clinical disease develops, then preventive measures can be applied to those sites at a much earlier stage. This could have a significant impact on periodontal treatment in the future.

\section{ACKNOWLEDGMENTS}

This work was supported by NIH/NIDR grants 2R01 DE07233 and 2T32 DE07014

Special thanks to Christopher Larson for technical assistance with the early stages of this project. We also thank Gregory Germaine, Charles Schachtele, and Larry Wolff for equipment and bacterial strains and Thomas Cafarella, Jolene Johnson, and James Miller for technical support.

\section{REFERENCES}

1. Albandar, J. M., and S. P. Lyngstadaas. 1995. PCR primers for the detection of Actinobacillus actinomycetemcomitans, abstr. 1299. J. Dent. Res. 74:174.

2. Alpagot, T., L. F. Wolff, Q. T. Smith, S. D. Tran, D. M. Aeppli, and N. A Hardie. Risk indicators for periodontal disease in a racially diverse urban population. J. Clin. Periodontol., in press.

3. Bodinka, A., H. Schmidt, B. Henkel, T. F. Flemmig, B. Klaiber, and H. Karch. 1994. Polymerase chain reaction for the identification of Porphyromonas gingivalis collagenase genes. Oral Microbiol. Immunol. 9:161-165.

4. Chamberlain, J. S., and J. R. Chamberlain. 1994. Optimization of multiplex PCRs, p. 38-46. In K. B. Mullis, F. Ferre, and R. A. Gibbs (ed.), The polymerase chain reaction. Birkhauser, Boston.

5. Chamberlain, J. S., R. A. Gibbs, J. E. Ranier, and C. T. Caskey. 1990. Multiplex PCR for the diagnosis of Duchenne muscular dystrophy, p. 272281. In M. Innis, D. Gelfand, J. Sninski, and T. White (ed.), PCR protocols: a guide to methods and applications. Academic Press, Orlando, Fla.

6. Choi, B. K., B. J. Paster, F. E. Dewhirst, and U. B. Göbel. 1994. Diversity of cultivable and uncultivable oral spirochetes from a patient with severe destructive periodontitis. Infect. Immun. 62:1889-1895.

7. Chuba, P. J., K. Pelz, G. Krekeler, T. S. De Isele, and U. Göbel. 1988. Synthetic oligodeoxynucleotide probes for the rapid detection of bacteria associated with human periodontitis. J. Gen. Microbiol. 134:1931-1938.

8. Dale, P., J. Johnson, and C. Schachtele. 1996. Detection of fimbrial genes in Actinomyces with polymerase chain reaction, abstr. 609. J. Dent. Res. 75:94.

9. Dewhirst, F. E., and B. J. Paster. 1991. DNA probe analyses for the detection of periodontopathic bacteria in clinical samples, p. 367-377. In S. Hamada, S. C. Holt, and J. R. McGhee (ed.), Periodontal disease: pathogens and host immune responses. Quintessence, Tokyo.

10. Dix, K., S. M. Watanabe, S. McArdle, D. I. Lee, C. Randolph, B. Moncla, and D. E. Schwartz. 1990. Species-specific oligodeoxynucleotide probes for the identification of periodontal bacteria. J. Clin. Microbiol. 28:319-323.

11. Evans, M. J., R. T. Evans, and S. J. Greenberg. 1993. Detection of Porphyromonas (Bacteroides) gingivalis using PCR, p. 609-619. In G. D. Ehrlich and S. J. Greenberg (ed.), PCR-based diagnostics in infectious disease. Blackwell Scientific Publications, Boston.

12. Flemmig, T. F., S. Rüdiger, U. Hofmann, H. Schmidt, B. Plaschke, A. Strätz, B. Klaiber, and H. Karch. 1995. Identification of Actinobacillus actinomycetemcomitans in subgingival plaque by PCR. J. Clin. Microbiol. 33:3102-3105.

13. Gelfand, D. H., and T. J. White. 1990 . Thermostable DNA polymerases, p.
129-141. In M. Innis, D. Gelfand, J. Sninski, and T. White (ed.), PCR protocols: a guide to methods and applications. Academic Press, Orlando, Fla.

14. Goncharoff, P., D. H. Figurski, R. H. Stevens, and D. H. Fine. 1993. Identification of Actinobacillus actinomycetemcomitans: polymerase chain reaction amplification of lktA-specific sequences. Oral Microbiol. Immunol. 8:105-110.

15. Haffajee, A. D., and S. S. Socransky. 1994. Microbial etiological agents of destructive periodontal diseases. Periodontology 2000 5:78-111.

16. Kwok, S., and R. Higuchi. 1984. Avoiding false positives with PCR. Nature (London) 339:237-238.

17. Larsen, N., G. J. Olsen, B. L. Maidak, M. J. McCaughey, R. Overbeek, T. J. Macke, T. L. Marsh, and C. R. Woese. 1993. The ribosomal database project. Nucleic Acids Res. 21(Suppl.):3021-3023.

18. Leser, T. D. 1995. Quantitation of Pseudomonas sp. strain B13(FR1) in the marine environment by competitive polymerase chain reaction. J. Microbiol. Methods 22:249-262.

19. Leys, E. J., A. L. Griffen, S. J. Strong, and P. A. Fuerst. 1994. Detection and strain identification of Actinobacillus actinomycetemcomitans by nested PCR. J. Clin. Microbiol. 32:1288-1294.

20. Loesche, W. J., D. E. Lopatin, J. Stoll, N. van Poperin, and P. P. Hujoel 1992. Comparison of various detection methods for periodontopathic bacteria: can culture be considered the primary reference standard? J. Clin. Microbiol. 30:418-426.

21. Longo, M. C., M. S. Berninger, and J. L. Hartley. 1990. Use of uracil DNA glycosylase to control carry-over contamination in polymerase chain reaction. Gene 93:125-128.

22. Loos, B. G., D. W. Dyer, R. G. Genco, R. K. Selander, and D. P. Dickinson. 1993. Natural history and epidemiology of Porphyromonas gingivalis, p. 3-31. In H. Shah, D. Mayrand, and R. J. Genco (ed.), Biology of the species Porphyromonas gingivalis. CRC Press, Boca Raton, Fla.

23. Meier, A., D. H. Persing, M. Finken, and E. C. Böttger. 1993. Elimination of contaminating DNA with polymerase chain reaction reagents: implications for a general approach to detection of uncultured pathogens. J. Clin. Microbiol. 31:646-652.

24. Moore, W. E. C., and L. V. H. Moore. 1994. The bacteria of periodontal diseases. Periodontology 2000 5:66-77.

25. Page, R. C., G. C. Armitage, T. A. DeRouen, R. J. Genco, P. Hujoel, M. K Jeffcoat, K. S. Kornman, and R. C. Williams. 1995. Design and conduct of clinical trials of products designed for the prevention, diagnosis, and therapy of periodontitis. American Academy of Periodontology, Chicago.

26. Prince, A. M., and L. Andrus. 1992. PCR: how to kill unwanted DNA BioTechniques 12:358-360.

27. Relman, D. A. 1993 . Universal bacterial $16 \mathrm{~S}$ rDNA amplification and sequencing, p. 489-495. In D. H. Persing, T. F. Smith, F. C. Tenover, and T. J. White (ed.), Diagnostic molecular microbiology: principles and applications. American Society for Microbiology, Washington, D.C.

28. Savitt, E. D., M. N. Strzempko, K. K. Vaccaro, W. J. Peros, and C. K. French. 1988. Comparison of cultural methods and DNA probe analyses for the detection of Actinobacillus actinomycetemcomitans, Bacteroides gingivalis, and Bacteroides intermedius in subgingival plaque samples. J. Periodontol. 59:431-438.

29. Socransky, S. S., C. Smith, L. Martin, B. J. Paster, F. E. Dewhirst, and A. E. Levin. 1994. "Checkerboard” DNA-DNA hybridization. BioTechniques 17: 788-792.

30. Tønjum, T., and R. Haas. 1993. Identification of Actinobacillus actinomyce temcomitans by leukotoxin gene-specific hybridization and polymerase chain reaction assays. J. Clin. Microbiol. 31:1856-1859.

31. van Winkelhoff, A. J., T. J. M. van Steenbergen, and J. de Graaff. 1993. Occurrence and association with disease, p. 33-42. In H. Shah, D. Mayrand, and R. J. Genco (ed.), Biology of the species Porphyromonas gingivalis. CRC Press, Boca Raton, Fla.

32. Wahlfors, J., J. H. Meurman, P. Vaisanen, P. Alakuijala, A. Korhonen, H Torkko, and J. Janne. 1995. Simultaneous detection of Actinobacillus actinomycetemcomitans and Porphyromonas gingivalis by a rapid PCR method. J. Dent. Res. 74:1796-1801.

33. Watanabe, K., and T. O. Frommel. 1993. Detection of Porphyromonas gingivalis in oral plaque samples by use of the polymerase chain reaction. J. Dent. Res. 72:1040-1044

34. Wolff, L. F., D. M. Aeppli, B. L. Pihlstrom, L. Anderson, J. L. Stoltenberg, J. B. Osborn, N. A. Hardie, C. E. Shelburne, and G. E. Fisher. 1993. Natura distribution of 5 bacteria associated with periodontal disease. J. Clin. Periodontol. 20:699-706.

35. Wolff, L. F., G. Dahlèn, and D. M. Aeppli. 1994. Bacteria as risk markers for periodontitis. J. Periodontol. 64:498-510.

36. Zambon, J. J., and V. I. Haraszthy. 1995. The laboratory diagnosis of periodontal infections. Periodontology 2000 7:69-82. 